Vol 3. No 2. Agustus 2019

ISSN 2580-5029

\title{
STUDI ETNOBOTANI MASYARAKAT DI SEKITAR KAWASAN HUTAN BEDUGUL BALI
}

\author{
I Dewa Putu Darma ${ }^{*}$, Arief Priyadi ${ }^{2}$ dan Rajif Iryadi 3 \\ ${ }^{1,2,3}$ Pusat Penelitian Konservasi Tumbuhan dan Kebun Raya - LIPI \\ 1, 2,3 Balai Konservasi Tumbuhan Kebun Raya "Eka Karya” Bali - LIPI, Tabanan-Bali, Indonesia \\ *Email: idpdarma@gmail.com
}

\begin{abstract}
The Ethnobotany study of society advantage knowing plant species that be used and this usefulness. This study purpose identification plant's utilization and local wisdom in Bedugul area. This method is purposive sampling that based profession with interview to Dukun, Baten, housewife, Farmer, craftsmen and builder. Filed data were processed with quantitative to get the benefit index (BI) on 181 species. Top ten species have been the highest of BI such as: Musa paradisiaca (0.026718), Arenga pinnata (0.022901), Artocarpus integer (0.015267), Cocos nucifera (0.015267), Colocasia esculenta (0.015267), Curcuma domestica (0.015267), Schizostachyum brachyckadum (0.015267), Moringa oleifera (0.01145), Aleurites moluccanus (0.01145) \& Allium sativum (0.01145). Four of them have rare status i. e: Borassus flabellifer, Alstonia scholaris, Eeucresta horsfieldii \& Saurauia bracteosa. Bali culture which has reserved with conservation education (Tumpek Wariga ceremony, Wana Kertih \& Danau Kertih) makes the environment sustainability.
\end{abstract}

Keywords: Ethnobotany, society, culture, environment

Keywords: Ethnobotany, society, culture, environment

\begin{abstract}
ABSTRAK
Studi etnobotani masyarakat di kawasan Bedugul- Bali bermanfaat mengetahui pemenfaatan dan jenis tumbuhan yang digunakan. Tujuan penelitian untuk mengidentifikasi pemanfaatan tumbuhan dan menggali kearifan lokal di sekitar kawasan Bedugul. Studi ini dilakukan dengan metode wawancara secara purposive sampling pada profesi Dukun,Tukang baten, Ibu rumah tangga, Petani, Pengerajin dan Tukang bangunan. Data lapangan dilakukan analisis kuantitatif untuk mencari indeks manfaat (IM) pada 181 jenis tumbuhan. Sepuluh jenis tertinggi IM diantaranya: Musa paradisiaca (0,026718), Arenga pinnata (0,022901), Artocarpus integer $(0,015267)$, Cocos nucifera $(0,015267)$, Colocasia esculenta $(0,015267)$, Curcuma domestica $(0,015267)$, Schizostachyum brachyckadum $(0,015267)$, Moringa oleifera $(0,01145)$, Aleurites moluccanus $(0,01145)$ dan Allium sativum $(0,01145)$. Empat diantaranya memiliki status langka yaitu: Borassus flabellifer, Alstonia scholaris, Eeucresta horsfieldii dan Saurauia bracteosa. Budaya Bali yang syarat dengan pendidikan konservasi (UpacaraTumpek Wariga,Wana Kertih dan Danau Kertih), menjadikan lingkungan terjaga kelestariannya.
\end{abstract}

Kata Kunci: Etnobotani, masyarakat, budaya, lingkungan 


\section{BIOTROPIC The Journal of Tropical Biology}

Vol 3. No 2. Agustus 2019

ISSN 2580-5029

\section{PENDAHULUAN}

Kawasan hutan Bedugul Bali mempunyai peran penting sebagai kawasan penyangga air bagi masyarakat Bali Utara buleleng dan Bali Selatan Badung, Denpasar dan Tabanan, (Suji, 2005). Selanjutnya Windia \& Winguna, 2013, menyebutkan kawasan hutan Bedugul Bali termasuk kawasan hulu Catur Angga Batukaru. Kawasan ini sangat menentukan keberlangsungannya subak Jati Luwih Sebagai Cagar Budaya Warisan Dunia

Kawasan ini pernah diusulkan pada Simposium Analisis Daya Dukung dan Daya Tampung Sumber Daya Air di KawasanTridanau Beratan, Buyan dan Tamblingan Bali . Diselenggarakan oleh UPT Balai Konservasi Tumbuhan Kebun Raya "Eka Karya"Bali-LIPI bekerja sama dengan Badan Pengendalian Dampak Lingkungan Daerah Provinsi Bali tahun 2005 pengelolaanya dengan Konsep Cagar Biosfer (Biosphere Reserve). Konsep Cagar Biosfer mempunyai fungsi sebagai agen untuk mengintegrasikan dan mengkoordinasikan upaya semua pemangku kepentingan tanpa melupakan hak secara historis kepemilikan lahan atau sumber daya (Darnaedi et al., 2005). Cagar biosfer juga bertujuan mencegah hilangnya pengetahuan local dan keanekaragaman budaya (UNESCO, 2010).

Masyarakat disekitar kawasan hutan Bedugul Bali mempunyai peran penting untuk menjaga dan melestarikan keanekaragaman tumbuhan tersebut. Selanjutnya Witono et al., 2012 menyebutkan Strategi konservasi dunia memiliki 3 sasaran yaitu 1) memelihara proses-proses ekologi dan sistem pendukung kehidupan, 2) konservasi keanekaragaman genetik dan 3) menjamin pemanfaatan jenis dan ekosistem yang berkesinambungan. Selanjutnya Berkes (2012) menyebukan konservasi harus melibatkan peran serta masyarakat lokal menyangkut pengetahuan, minat, kebutuhan sosial dan ekonomi mereka.

Etnobotani adalah ilmu yang mendalami hubungan budaya manusia dengan alam nabati sekitarnya (Rifai \& Waluyo 1992). Proses identifikasi tumbuhan oleh etnis lokal merupakan bagian penting dalam pengenalan jenis, kulvitas tumbuhan berkaitan dengan pemanfaatan, komunikasi, pengelolaan yang merupakan awal dalam penelitian etnobotani (Batoro, 2015). Upaya pelestarian dan pemanfaatannya kajian etnobotani masyarakat di sekitar kawasan hutan danau Buyan, Tamblingan dan Beratan perlu digali. Menurut Bantoro (2015) beberapa kajian etnobotani dalam pemanfaatan tumbuhan sebagai bahan pangan, bangunan, kayu bakar, obat, racun, ritual adat dan pakan ternak, banyak diketahui oleh masyarakat Indonesia, namun dalam catatan ilmiah saat ini masih terbatas.

Penelitian ini bertujuan untuk mengidentifikasi pemanfaatan tumbuhan secara berkesinambungan. Serta menggali 
kearifan lokal yang sarat dengan pendidikan konservasi disekitar kawasan hutan danau Buyan, Tamblingan dan Beratan. Diharapkan hasil penelitian ini dapat dijadikan rujukan bagi pemerintah untuk pengelolaan kawasan hutan danau Buyan, Tamblingan dan Beratan.

\section{METODE}

Penelitian dilakukan pada tanggal 09 sampai 14 Maret 2015. Penelitian dilakukan di Desa Gobleg dan Munduk - Kecamatan Banjar, Desa Pancasari dan Desa Wanagiri Kecamatan Sukasada serta Desa Candikuning - Kecamatan Baturiti. Desa ini berbatasan dengan kawasan hutan Danau, Buyan, Tamblingan dan Beratan. Lokasi penelitaian berada pada $8,224^{\circ}-8,320^{\circ}$ LS dan $115,085^{\circ}$ - 115,20으 BT (Gambar 1.)

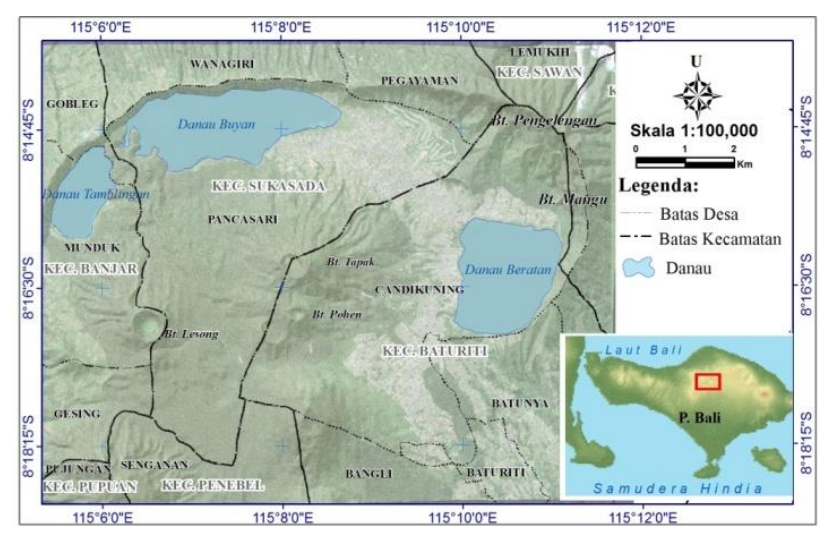

Gambar 1. Lokasi penelitian (sumber: data citra Pleaides 2014 Kebun Raya "Eka Karya" Bali \& peta Rupa Bumi Indonesia, 2019).

Studi etnobotani dilakukan dengan wawancara secara purposive sampling pada masyarakat kunci yang berpropesi sebagai Dukun,Tukang baten, Ibu rumah tangga, Petani, Pengerajin dan Tukang bangunan. Data yang diamati meliputi nama lokal, nama ilmiah, famili, bagian tumbuhan yang digunakan, cara penggunaannya dan menginventaris kearifan lokal yang syarat dengan pendidikan konservasi. Data yang diperoleh dilapangan disajikan dalam bentuk tabulasi, kemudian dianalisa secara deskriptif dengan pendekatan kuantitatif. Sedangkan untuk mengetahui nilai indek manfaat (IM) sesuatu jenis tanaman. dilakukan dengan asumsi semakin banyak jenis tanaman kegunaannya, semakin tinggi nilai IM-nya (Bantoro, 2015), perhitungan IM dapat diperoleh dengan persamaan:

$$
\mathrm{IM}=\frac{\mathrm{Ji}}{\mathrm{N}} \times 100 \%
$$

Keterangan:

$\mathrm{IM}=$ Indeks manfaat

$\mathrm{Ji}=$ Jumlah kemunculan kegunaan sesuatu jenis

$\mathrm{N}=$ Jumlah total kemunculan kegunaan semua jenis

\section{HASIL DAN PEMBAHASAN}

\section{Keragaman Tumbuhan Berguna}

Hasil penelitian terdapat 181 jenis tumbuhan yang digunakan oleh masyarakat di sekitar kawasan hutan Danau Buyan, Tamblingan dan Beratan. Dari jumlah tersebut terdapat 11 kelompok pemanfaatannya yaitu untuk: 1) Obat 69 jenis, 2) Upacara keagamaan 105 jenis, 3) Aromatik 8 jenis, 4) Bahan bangunan 15 jenis, 5) Bahan bumbu 9 jenis, 6) Bahan kerajinan (musik, temali, anyaman) sebanyak 8 jenis, 7) Pakan ternak 12 jenis, 8) Bahan pangan 6 jenis, 9) Pembungkus 6 jenis, 10) Pewarna alami 6 jenis dan 11) Sayuran 18 jenis. (Gambar.2) 




Gambar 2. Jumlah jenis tumbuhan berdasarkan kelompok pemanfaatan oleh masyarakat di sekitar kawasan hutan Danau Buyan Tamblingan dan Beratan. (Keterangan: 1. Obat, 2. Upacara keagamaan, 3. Aromatik, 4. Bahan bangunan, 5. Bahan bumbu, 6. Bahan kerajinan, 7. Pakan ternak, 8.Bahan pangan, 9. Bahan pembungkus makanan, 10. Pewarna alami, 11. Sayuran) (sumber: Pengolahan data lapangan, 2018)

Purwanto dan Walujo 1992, menyebutkan pengelompokan kegunaan sumberdaya alam hayati yaitu tumbuhan obat, hias, aromatik, penghasil pangan, pakan ternak, penghasil pestisida nabati, penghasil serat, bahan pewarna dan tanin, penghasil bahan bangunan, keperluan ritual adat dan keagamaan, kerajinan, penghasil kayu bakar sebagai tolak bala.

Tingginya penggunaan jenis untuk obat sebanyak 69 jenis dan upacara keagamaan sebanyak 105 jenis. Nampaknya terkait dengan masyarakat Bali menggunakan tumbuhan sebagai obat karena mereka percaya bahwa obat tradisional lebih berkhasiat dan tidak menimbulkan efek sampingan. Pengetahuan masyarakat Bali tentang pengobatan tradisional telah tertera dalam lontar Usada Bali yang memuat sistem pengobatan, bahan obat serta cara pengobatannya secara yang telah ada sejak ratusan tahun yang lalu (Nala, 2007) dan masyarakat Bali tidak bisa lepas dari upacara. Selanjutnya Pramita, 2013 menyebutkan kepercayaan suatu masyarakat adat tidak dapat dipisahkan dari tumbuhan.

Berdasarkan pemanfaatan jenisnya 10 besar jenis tumbuhan utama yang digunakan oleh masyarakat di sekitar kawasan hutan Danau Buyan, Tamblingan dan Beratan. Berdasarakan nilai indek pemanfaatanya tertinggi diduduki oleh Musa paradisiaca/ pisang (IM. 0,026718) kemudian diikuti oleh Arenga pinnata/ aren (IM. 0,022901), Artocarpus integer/ nangka (IM. 0,015267), Cocos nucifera/ kelapa (IM. 0,015267), Colocasia esculenta/ keladi(IM. 0,015267), Curcuma domestica/ kunyit (IM. 0,015267), dan Schizostachyum brachyckadum/ tiing tali( IM. 0,015267), Moringa oleifera/ kelor (IM. 0,015267), Aleurites moluccanus/ tingkih (IM. 0,015267), dan Allium sativum/ kesuna. (IM. 0,015267) Gambar 3. 


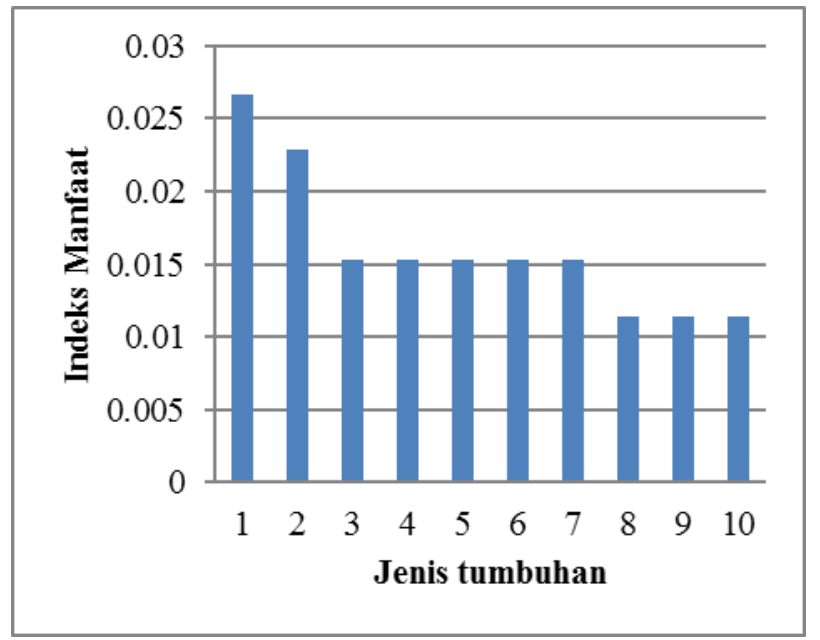

Gambar 3. Nilai Indeks Manfaat 10 jenis tumbuhan utama di sekitar kawasan hutan Danau Buyan dan Danau Tamblingan. (Keterangan: 1. Musa paradisiaca L., 2. Arenga pinnata (Wurmb) Merr., 3. Artocarpus integer (Thumb) Merr, 4. Cocos nucifera L., 5. Colocasia esculenta, 6. Curcuma domestica Val, 7. Schizostachyum brachyckadum (Kurz) Kurz, 8. Moringa oleifera, 9. Aleurites moluccanus (L.) Willd., 10. Allium sativum L. (Sumber: pengolahan data lapangan, 2018)

\section{Status konservasinya}

Dari 181 tumbuhan yang digunakan oleh masyarakat di disekitar kawasan hutan Danau Buyan, Tamblingan dan Beratan. Beberapa jenis yang status konservasinya terdaftar di The IUCN Red List of Threatened Species.Terdapat pula satu jenis tumbuhan dengan status endangered / genting yaitu Borassus flabellifer./ ental. Tumbuhan ini tidak termasuk 10 besar jenis tumbuhan utama, Masyarakat disekitar kawasan ini mendapatkan Borassus flabellifer dengan cara membeli di pasar karena tanaman ini tidak cocok tumbuh di kawasan ini. Menyimak hal tersebut tanaman ini dimanfaatkan oleh masyarakat dan berstatus langka maka dituntut suatu upaya konservasinya harus dilakukan pada Borassus flabellifer.

Ada juga terdaftar sebagai tumbuhan langka Indonesia, yaitu Alstonia scholaris. dan Euchresta horsfieldii (Mogea et al., 2001). Penggunaan tumbuhan Alstonia scholaris oleh masyarakat disekitar hutan danau Buyan, Tamblingan dan Beratan sebagai obat dan upacara keagamaan. (Meena et al. (2011) menyebutkan bahwa ekstrak Alstonia scholaris. memiliki beberapa aktivitas farmakologi yaitu sebagai antioksidan, antibakteri, hepatoprotektif, antikanker, antidiabetes, antistress, antidiare dan lain sebagainya. Euchresta horsfieldii digunakan untuk obat. Tirta et al. (2010) menyebutkan bahwa terdapat 40 senyawa metabolit sekunder pada Euchresta horsfieldii. Salah satunya adalah senyawa Kaur-16-ene yang terdapat pada batang. Senyawa ini merupakan salah satu turunan dari senyawa Kaur yang dapat berfungsi sebagai antikanker. Masyarakat juga mempercayai bahwa biji tumbuhan ini dapat digunakan sebagai obat kuat penambah gairah (aprodisiak). Wihermanto et al. (2009) menyebutkan dalam penelitiannya bahwa status populasi Saurauia bracteosa mengalami perubahan kategori menjadi endangered/ genting. Masyarakat di sekitar kawasan hutan Danau Buyan, Tamblingan dan Beratan memanfaatkan tumbuhan ini sebagai pakan ternak. Terjaganya kelestarian biodiversitas tumbuhan ini, diperlukan suatu upaya konservasi eksitu (Sutomo \& 
Mukaromah, 2010). Selanjutnya untuk tujuan restorasinya perlu diketahui habitatnya dan cara perbanyakannya

\section{Nilai Konservasi Dalam Budaya}

Masyarakat Desa Gobleg, Muduk kecamatan Banjar, Desa Wanagiri, Pancasari Kecamatan Sukasada dan Desa Candikuning Kecamatan Baturiti. Penduduknya sebagaian besar beragama Hindu. Bagi umat Hindu, tumbuh-tumbuhan hampir selalu hadir dalam prosesi ritualnya (Waluyo, 2017). Kehidupan masyarakat Bali secara umum didasari atas filsafah Tri Hita Karana. Tiga hubungan manusia untuk menuju kebahagian yaitu hubungan manusia dengan Tuhan, manusia dengan manusia dan manusia dengan lingkungan (Purnomohadi, 1993). Terjalinnya hubungan tersebut didasari atas pengorbanan suci (yadnya).

Pelaksanaan Upacara Tumpek Wariga masyarakat di sekitar kawasan hutan danau Buyan, Tamblingan dan Beratan dilakukan oleh masyarakat yang mempunyai perkebunan seperti cengkeh, kopi dan buahbuahan. Upacara ini merupakan wujud bakti kepada Tuhan sebagai penciptanya.Bali yang ajeg tidak bisa lepas dari upacara dan upacara tidak bisa lepas dari tumbuhan hal ini bermakna Bali akan ajeg apa bila lingkungannya lestari.

Keramat dan suci bermakna sebagai wujud perlidungan terhadap lingkungan. Pelaksanaannya di masyarakat dilakukan dengan memberi sesajen dan kain poleng (hitam putih) atau putih kuning. Beberapa jenis pohon yang dikeramatkan seperti pohon beringin (Ficus bejamina), keroya (Ficus lacor) keresek (Ficus sp.) pada umumnya pohon yang besar. Hal ini terkait dengan pelestarian sebagai pohon penghasil biji dan pohon inang tumbuhan epifit. Tradisi menebang pohon dengan menamcapkan cabangnya pada pangkal pohon yang ditebang. Cabang batang yang ditancapkan tersebut disebut dengan nama tanaman penanggeh (sementara) sebagi wujud janji untuk menanam pohon kembali. Selanjunya Windia \& Wiguna (2013), mengungkapkan esensi kearifan lokal adalah komitmen yang tinggi terhadaf kelestarian alam, rasa religiusitas, subjektivikasi manusia dan kontruksi pada persembahan, harmoni, kebersamaan dan keseimbangan untuk kebahagian (jagadhita) berkelanjutan.

Salah satu kontribusi dan peran penting dari kelompok masyarakat adalah manajemen kebun-pekarangan rumah untuk mendukung ketahanan pangan dan pengembangannya pada umumnya diarahkan untuk memenuhi sumber pangan sehari-hari, sehingga seringkali diungkapkan sebagai lumbung hidup atau warung hidup (Rahayu, 2011). Merujuk pada Rahayu, (2011) dan Hakim (2014) manajemen kebun pekarangan rumah telah dilaporkan mengandung berbagai jenis tanaman untuk memenuhi kebutuhan sehari-hari, kebun dan pekarangan rumah relatif mudah dikelola oleh keluarga petani tanpa melibatkan permodalan dan teknologi modern. Di 
Indonesia, ekosistem kebun dan pekarangan rumah adalah salah satu pusat bagi keanekaragaman hayati di area pemukiman penduduk di pedesaan

Banyak penelitian sebelumnya menyatakan bahwa kebun dan pekarangan rumah adalah habitat bagi keanekaragam tumbuhan (Rahayu, 2011; Hakim, 2014). Selanjutnya Sujarwo dan Caneva (2015), mengungkapkan bahwa Masyarakat desa tardisional di Bali mempertahankan kelestarian lingkungan mereka dengan menanam berbagai jenis tanaman untuk berbagai keperluan di kebun rumah mereka. Hal ini menunjukan pekarangan sangat strategis digunakan untuk mengkoservasi jenis tumbuhan yang digunakan sehari-hari.

\section{KESIMPULAN}

Pemanfaaatan jenis tumbuhan oleh masyarakat disekitar hutan danau Buyan, Tambling dan Beratan terdapat 11 kelompokan yaitu 1 Obat, 2 Upacara keagamaan, 3 Aromatik, 4 Bahan bangunan, 5 Bahan bumbu, 6 Bahan kerajinan(musik, temali , anyaman), 7 Pakan ternak, 8 Bahan pangan, 9 Pembungkus makanan, Pewarna alami dan 11 Sayuran. Musa paradisiacal merupakan jenis yang memiliki nilai indeks manfaat tertinggi (IM: 0,026718). Berdasarkan status konservasinya 4 jenis termasuk langka yaitu Borassus flabellife, Alstonia scholaris, Eeucresta horsfieldii dan Saurauia bracteosa. Budaya yang syarat dengan pendidikan konservasi yaitu Tumpek Wariga, Danau kertih, wana kertih merupakan upacara yang mewujudkan bentuk bakti dan penghormatan terhadap tumbuhan. Keramat dan suci sebagai wujud perlindungannya. Sedangkan tradisi menamcapkan cabang pohon pada bekas tebangan (Tanaman penanggeh) merupakan janji untuk menam kembali.

\section{UCAPAN TERIMAKASIH}

BKT Kebun Raya "Eka Karya” bali -LIPI yang mendanai kegiatan lapangan dalam tolak ukur kegiatan kelompok peneliti Konservasi dan Restorasi, serta staff teknisis lapangan dalam membantu pelaksanaan kegiatan lapangan.

\section{DAFTAR PUSTAKA}

Batoro, J. 2015. Pengelolaan Lingkungan: Dengan Pendekatan EtnobiologiEtnobotani. Universitas Brawijaya Press., Malang.

Berkes, F. 2012. Sacred Ecologi $3^{\text {rd }}$ Edition. Routledge taylor \& Francis Group, New York.

Darnaedi, D., Siregar, M., Soedjito, H., dan Sukarra, E. 2005. Konsep Cagar Biosfer: Alternatif Pengelolaan Kawasan Tridanau Berat, Buyan dan Tamblingan Provinsi Bali, Prosiding Simposium Analisis Daya Dukung dan Daya Tampung Sumber Daya Air di Kawasan Tri-danau Beratan, Buyan dan Tamblingan, UPT Balai Konservasi Tumbuhan Kebun Raya "Eka Karya" Bali Bekerjasama Dengan Badan Pengendalian Dampak Lingkungan Pemerintah Daerah Provinsi Bali.

Hakim, L. 2014. Etnobotani dan Manajemen Kebun Pekarangan Rumah, Ketahanan Pangan, Kesehatan dan Agrowisata. 
Penerbit Selaras Anggota IKAPI Jatim, $252 \mathrm{~h}$.

Meena, A. K., Nitika, G., Jaspreet, N., Meena, R. P., \& Rao, M. M. (2011). Review on ethanobotany, phytochemical and pharmacological profile of Alstonia scholaris. International Research Journal of Pharmacy. 2(1), 49-54.

Mogea, JP., Gandawidjaja, D., Wiriadinata, H., \& Irawati, REN. 2001. Tumbuhan Langka Indonesia. Pusat Penelitian dan Pengembangan Biologi-LIPI, Balai Penelitian Botani, Herbarium Bogoriense. 86 : Bogor.

Nala, N. 2007. Usada Bali: Tinjauan Filosofis dan Peranannya dalam Ekowisata. Prosiding Seminar Konservasi tumbuhan Usada Bali dan peranannya dalam mendukung Ekowisata. UPT Balai Konservasi Tumbuhan Kebun Raya "Eka Karya"” Bali - LIPI bekerja sama dengan Universitas Udayana dan Universitas Hindu Indonesia. Tabanan

Purnomohadi, N. 1993. Technical Excursion. The 5 th IFLA, Eastern Regional Conference Bali.

Purwanto Y. dan Walujo EB. 1992. Etnobotani Suku Dani di Lembah Baliem-Irian Jaya : Suatu Telaah tentang Pengetahuan dan Pemanfaatan Sumber Daya Alam Tumbuhan. Di dalam: Seminar dan Lokakarya Nasional Etnobotani; Cisarua-Bogor, 19-20 Februari 1992. Bogor: Departemen Pendidikan dan Kebudayaan RI, Departemen Pertanian RI, LIPI, Perpustakaan Nasional RI. Hal: 132-148.

Rahayu, M. (2011). Keanekaragaman tanaman pekarangan dan pemanfaatannya di desa Lampeapi, Pulau Wawoni-Sulawesi Tenggara. Jurnal Teknologi Lingkungan. 6 (2).

Rifai .M. dan Waluyo, EB. 1992. Etnobotani dan Pengembangan Tetumbuhan Pewarna Indonesia: Ulasan Suatu Pengamatan di Madura. dalam: Seminar dan Lokakarya Nasional Etnobotani; Cisarua-Bogor, 19-20 Februari 1992. Bogor: Departemen Pendidikan dan Kebudayaan RI, Departemen Pertanian RI, LIPI, Perpustakaan Nasional RI. Hal: 119-126.

Sujarwo, W and Caneva, G. 2015. Ethnobotanical Study of Cultivated Plants in Home Gardens of Traditional Villages in Bali (Indonesia), Human Ecology: An Interdisciplinary Journal, Speringer. pp1-10.

Suji, NW. 2005. Kebijakan Pembangunan Kawsan Tri-danau Beratan, Buyan dan Tamblingan, Prosiding Simposium Analisis Daya Dukung dan Daya Tampung Sumber Daya Air di Kawasan Tri-danau Beratan, Buyan dan Tamblingan, UPT Balai Konservasi Tumbuhan Kebun Raya "Eka Karya" Bali Bekerjasama Dengan Badan Pengendalian Dampak Lingkungan Pemerintah Daerah Provinsi Bali. hal, 49-57.

Sutomo \& Mukaromah, L. 2010. Autoekologi Purnajiwa (Euchresta horsfieldii (Lesch.) Benn. (Fabaceae) di Sebagian Kawasan Hutan Bukit Tapak Cagar Alam Batukahu Bali. Jurnal Biologi Udayana. 14(1), 24-28.

Tirta, IG., Ardaka, IM., dan Darma, IDP. 2010. Studi fenologi dan senyawa kimia pronojiwo (Euchresta horsfieldii (Lesch.) Benn.). Buletin Penelitian Tanaman Rempah dan Obat. 21(1), 2836.

UNESCO. 2010. Lesson From Biosphere Reserve in the Asia-Pacific Region, and a Way Forward: A regional review of biosphere reserve in Asia \& the Pacific to achieve sustainable development. UNESCO Office.

Walujo, EB. 2017. Sumbangan Ilmu Etnobotani dalam Memfasilitasi Hubungan Manusia Dengan Tumbuhan dan Lingkungannya. Jurnal Biologi Indonesia. $7(2)$. 
Wihermanto, Widyatmoko, D., dan Haryani, $\mathrm{T}$ S. 2004. Asosiasi dan Status Populasi Lotrok (Saurauia bracteosa DC.) dan Ki Leho Beureum (Saurauia cauliflora DC.) sebagai Tumbuhan Terancam Punah di Taman Nasional Gunung GedePangrango, Jawa Barat. Berkala ilmiah Biologi. 3(3), 201-212.

Windia, IW., \& Wiguna, WAA. 2013. Subak warisan budaya dunia. Udayana University Press., Denpasar.

Witono, JR., Purnomo, DW., Usmadi, D., Pribadi, DO., Asikin, D., Magandhi, M., Sugiarti dan Yuzammi, 2012. Rencana Pengembangan Kebun Raya IndonesiaLIPI, hal. 15. 